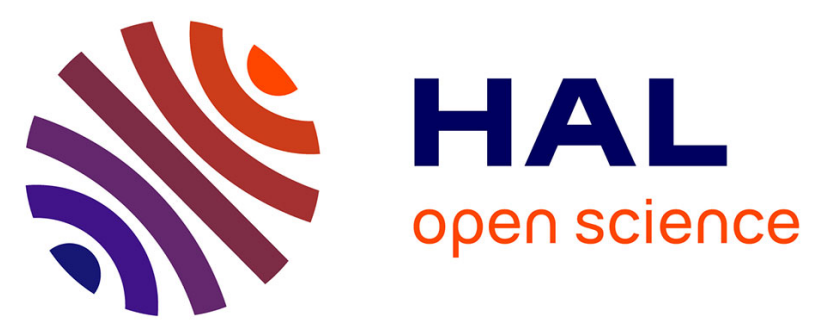

\title{
The influence of dispersion and distribution of ultrafine kaolinite in polyamide- 6 on the mechanical properties and fire retardancy
}

M. Batistella, A. S. Caro-Bretelle, B. Otazaghine, Patrick Ienny, R. Sonnier, C. Petter, J. M. Lopez-Cuesta

\section{To cite this version:}

M. Batistella, A. S. Caro-Bretelle, B. Otazaghine, Patrick Ienny, R. Sonnier, et al.. The influence of dispersion and distribution of ultrafine kaolinite in polyamide- 6 on the mechanical properties and fire retardancy. Applied Clay Science, 2015, 116-117, pp.8-15. 10.1016/j.clay.2015.07.034 . hal-02914339

\section{HAL Id: hal-02914339 \\ https://hal.science/hal-02914339}

Submitted on 25 May 2021

HAL is a multi-disciplinary open access archive for the deposit and dissemination of scientific research documents, whether they are published or not. The documents may come from teaching and research institutions in France or abroad, or from public or private research centers.
L'archive ouverte pluridisciplinaire HAL, est destinée au dépôt et à la diffusion de documents scientifiques de niveau recherche, publiés ou non, émanant des établissements d'enseignement et de recherche français ou étrangers, des laboratoires publics ou privés. 


\title{
The influence of dispersion and distribution of ultrafine kaolinite in polyamide- 6 on the mechanical properties and fire retardancy
}

\author{
M. Batistella a,b ${ }^{\text {, A.S. Caro-Bretelle }}{ }^{\mathrm{a}, *}$, B. Otazaghine ${ }^{\mathrm{a}}$, P. Ienny ${ }^{\mathrm{a}}$, R. Sonnier ${ }^{\mathrm{a}}$, C. Petter ${ }^{\mathrm{b}}$, J.M. Lopez-Cuesta ${ }^{\text {a }}$ \\ a C2MA, Ecole des Mines d'Alès, 6 Avenue de Clavières, 30319 AlèsFrance \\ b Universidad Federal do Rio Grande do Sul, Av. Bento Gonçalves, 8500 Porto Alegre, RS, Brazil
}

\begin{abstract}
A B S T R A C T
The aim of this paper is to demonstrate that morphological particle properties inside the polymer matrix are responsible for the variability of mechanical properties (elasticity, strength, resilience) and fire retardancy properties. Ultrafine kaolinites were modified and employed to obtain composites of polyamide. These composites were characterized by means of mechanical (tensile static and dynamic tests) and fire retardancy properties (cone calorimeter). Their morphological properties differed significantly according to the aspect ratio and surface treatment of the kaolinites. These morphologies, characterized by the particle dispersion (interparticle distance ID) and size distribution (median diameter MD) in the polymer matrix, were directly related to the mechanical properties. The experimental results demonstrate the sensitivity of strength, resilience and flammability to particle dispersion and distribution. The yield stress decreases with the increase of MD, the resilience decreases with the increase of ID with a critical ID value from which the composite became brittle, and the pHRR increases with the increase of ID.
\end{abstract}

Keywords:

Mechanical properties

Microstructure

Image analysis

Kaolinite

Flame retardancy

\section{Introduction}

Polymers have been widely used for more than 50 years due to their good mechanical and physical properties and easy processing. Nevertheless, they have a very poor reaction to fire (Gérard et al., 2010). Hence, improvement of the polymer fire reaction remains a constant challenge, considering new applications and more and more stringent standards.

Fire retardancy can be performed through different mechanisms involving various kinds of flame retardant systems. Among flame retardants, metal hydroxides, mainly aluminium and magnesium hydroxides (ATH, MDH), offer the best opportunity to meet environmental requirements. But, they require high loadings (often up to $65 \mathrm{wt} . \%)$ and thereby lead to poor mechanical properties. Interestingly, nanoparticles can be used alone and entail a more progressive heat release, but the total heat release remains the same (Bourbigot et al., 2000; Laoutid et al., 2006; Riva et al., 2002). Nanoparticles can also be used in combination with the usual flame retardants at a lesser global loading. This kind of combination involved mainly organomodified mineral nanoparticles such as layered silicates, e.g. montmorillonites (Mt) to improve flame retardancy (Blumstein, 1965; Fina et al., 2006; Giannelis, 2004; Gilman et al., 2000; Laachachi et al., 2005, 2009; Peeterbroeck et al., 2007; Rothon and Hornsby (1996)). Nevertheless, the processability of composites containing Mt limits their percentage

\footnotetext{
* Corresponding author.

E-mail address: Anne-Sophie.Caro@mines-ales.fr (A.S. Caro-Bretelle).
}

of incorporation, used alone or in combination (always under $10 \mathrm{wt} . \%$ by mass fraction composites Mt/polypropylene-grafted-maleic anhydride (PP-g-MA) (Blumstein, 1965), Mt/polyimide (PI) (Giannelis, 2004), Mt/polyamide (PA6) (Gilman et al., 2000), and Mt/ethyl vinyl acetate (EVA) (Peeterbroeck et al., 2007) to obtain intercalated or exfoliated nanostructures).

The modes-of-action of organomodified layered silicates to decrease the heat release can be the creation of a gas and thermal barrier layer (Fina et al., 2006; Laachachi et al., 2005; Peeterbroeck et al., 2007), the modification of the polymer degradation: heterogeneous catalysis associated to a char structure (Fina et al., 2006; Peeterbroeck et al., 2007), the modification of the thermal diffusivity (Friederich et al., 2010), the reduction of the macromolecular mobility (around or inside the silicate layers) (Laachachi et al., 2005), the increase of polymer viscosity (Razak et al., 2012) or the trapping of radicals formed during the thermal degradation (Laachachi et al., 2005). Recent study tried to promote another kind of ultrafine layered silicates: the kaolinites (Villanueva et al., 2010), which are already used in papermaking industry. Regarding the high aspect ratio of ultrafine kaolinite particles (Kaol), the main interest is the promotion of a huge interface regarding their loading as well as their potential as a reinforcing filler for loading that is significantly higher than usual nanosilicates such as organomodified montmorillonites (Swoboda et al., 2009). In this article, only a first step is carried out: Kaol is introduced alone, and for a kaolinite/PA6 composite, a good processability is still reached at $30 \mathrm{wt} . \%$. The broad potential use expected for this material needs investigation of the mechanical composite performances. Even if pristine particles are ultrafine, their level of 
dispersion in the matrix and their distribution may result in poor mechanical properties. Hence, a surface treatment would be advisable (the external surface of kaolinite could be covered with silanol groups, which are able to react with organic molecules).

The present study focuses on the use of pristine and organomodified Kaol (30\% by mass fraction) to improve both mechanical and flame retardancy properties of PA6 material. First, the composite morphologies are characterized by mean interparticle distance and particle median diameter. Then mechanical (static/dynamic) and fire tests (cone calorimeter) are performed. Finally, mechanical/fire properties are related to morphology characterization.

\section{Materials and methods}

\subsection{Materials and preparation}

The polyamide matrix (PA6) (density $1.14 \mathrm{~g} / \mathrm{m}^{3}$ ) used in this study was supplied by Rhodia under the trademark Technyl ${ }^{\circledR}$ C206.

Two kinds of Kaol particles were selected for this study:

- $\mathrm{K}_{1}$ particles: PARALUX® with a specific surface area (BET) of $12.2 \pm$ $1.5 \mathrm{~m}^{2} / \mathrm{g}$, an aspect ratio $\alpha$ of 10 and an average primary particle size $\left(d_{e l}\right)$ of $0.9 \mu \mathrm{m}$,

- $\mathrm{K}_{2}$ particles with a specific surface area (BET) of $19.9 \mathrm{~m}^{2} / \mathrm{g}$, an aspect ratio $\alpha$ of 5 and an average primary particle size $\left(d_{e l}\right)$ of $0.2 \mu \mathrm{m}$.

Both of them, were kindly supplied by Imerys (France) $\left(\mathrm{Al}_{2} \mathrm{O}_{3}\right.$ wt.\% $>38, \mathrm{~S}_{\mathrm{i}} \mathrm{O}_{2}$ wt.\% $>43$ ). Their chemical composition and structure are the same; they differ however in their size (see several cumulative percentile values in Table 1) and shape factor (see SEM micrographs of Fig. 1). Their measured densities were $2.78 \mathrm{~g} / \mathrm{m}^{3}$.

Surface treatment was carried out as follows. $50 \mathrm{~g}$ of kaolinites was dispersed in $500 \mathrm{ml}$ of an ethanol/water mixture (96/4). The $\mathrm{pH}$ of the solution was changed while stirring through the addition of acetic acid to reach a $\mathrm{pH}$ of 4.5. Coupling agents (treatment A: (3-aminopropyl)triethoxysilane $(\geq 98 \%)$; treatment E: (3-glycidyloxypropyl)trimethoxysilane $(\geq 98 \%)$ ) were supplied by Sigma-Aldrich (used as received) and added with a mass concentration of $10 \%$ of the kaolinite mass. In these surface treatments, amine groups have a good affinity with polyamide and epoxy groups can react with amine functions of polyamine chains. In theory both of these treatments are therefore expected to increase the particle matrix affinity and therefore modify mechanical and fire retardancy properties.

These mixtures were stirred for $6 \mathrm{~h}$. At the end of the reaction, the solvent was evaporated and the kaolinite was washed three times with ethanol to remove excess reagent.

Polyamide pellets were dried in a vacuum oven at $80^{\circ} \mathrm{C}$ for a minimum of $8 \mathrm{~h}$ prior to the compounding. A melt blending of PA6 with kaolinites was carried out on a co-rotating twin-screw extruder (Clextral, standard profile, length $=1200 \mathrm{~mm}$, speed $=250 \mathrm{rpm}$, screw diameter $=20 \mathrm{~mm}, \mathrm{~T}=180{ }^{\circ} \mathrm{C}$ to $\left.240{ }^{\circ} \mathrm{C}\right)$. The samples were injection moulded (Krauss Maffei KM 50 t, $\mathrm{T}=200-240{ }^{\circ} \mathrm{C}$, mould temperature $=80^{\circ} \mathrm{C}$ ) to obtain standardized specimens (ISO 527-2, 2012) for uniaxial tests (ASTM D638-14, 2014), notched test bars for Charpy impact (ASTM D6110-10, 2014) and square specimens for

Table 1

$\mathrm{K}_{1}$ and $\mathrm{K}_{2}$ characteristic size distributions

\begin{tabular}{lll}
\hline & $\mathrm{K}_{1}$ & $\mathrm{~K}_{2}$ \\
\hline$d_{90}(\mu \mathrm{m})$ & 2.5 & 0.23 \\
$d_{75}(\mu \mathrm{m})$ & 0.9 & 0.17 \\
$d_{50}(\mu \mathrm{m})$ & 0.5 & 0.13 \\
$d_{25}(\mu \mathrm{m})$ & 0.3 & 0.08 \\
\hline
\end{tabular}

cone calorimeter tests (ISO 5660-1, 2015; see Fig. 2a, b and c). All presented values are mean curves of at least five experiments.

Fillers were incorporated at $30 \%$ by mass fraction (equivalent to a volume incorporation rate $\phi_{p}=15 \%$ ). Such a filler fraction can be reached without hindering the processability. Six different formulations were thus prepared and are presented in Table 2. In the following, PA denotes the polyamide and $\mathrm{K}_{\mathrm{i}} \mathrm{PA}(\mathrm{i}=1,1 \mathrm{~A}, 1 \mathrm{E}, 2,2 \mathrm{~A}, 2 \mathrm{E})$ the kaolinite composite $\left(\mathrm{K}_{1}, \mathrm{~K}_{1 \mathrm{~A}}\right.$ with A treatment, $\mathrm{K}_{1 \mathrm{E}}$ with $\mathrm{E}$ treatment, $\mathrm{K}_{2}, \mathrm{~K}_{2 \mathrm{~A}}$ with $A$ treatment, $\mathrm{K}_{2 \mathrm{E}}$ with $\mathrm{E}$ treatment respectively). Kaolinites (coated or not) are introduced in polyamide at a same level of incorporation.

\subsection{Methods}

\subsubsection{Morphology by image analysis}

Tensile test specimens were cryo-fractured and the central zone of the samples (perpendicular to the flow direction) was observed using a Quanta SEM instrument (FEI, USA) under an accelerating voltage of $5 \mathrm{kV}$.

SEM micrographs were binarized and kaolinite stack sections were identified and filtered by surface area value with respect to the scale of observation and then numbered. This procedure was repeated for all the micrographs and the number of particles, identified for each magnification, was scaled by the surface analysis area. As selected objects did not have a well-defined shape, it was useful for comparison to consider each object as a disc occupying the same measured surface area. These discs were well described by their diameters, denoted $d$. For each composite, a distribution and a cumulated density in diameters were therefore obtained. For each sample particles (from aggregates to elementary ones) size distribution was obtained by image analysis (Aphelion $^{\mathrm{TM}} 3.2$ (ADCIS)) from a multi-scale analysis (from 100 to $5000 \mu^{2}$ (scale factor 100); from 15 to $100 \mu^{2}$ (scale factor 1000) and from 0.1 to $15 \mu^{2}$ (scale factor 20,000)). For each scale of observation several micrographs (at least 5 ) were used to cover the whole specimen surface area. Collecting data of each magnitude analysis, a filler diameter size distribution can be obtained from $d=0.18 \mu \mathrm{m}$ to $40 \mu \mathrm{m}$. This range of dimensions which is representative for the composite microstructure (fillers size distribution) must be related to composite properties.

The cumulative distribution can easily be fitted by a log-normal law:

$f(\ln (d))=\frac{1}{2}+\frac{1}{2} \operatorname{erf}\left(\frac{\ln (d)-M}{S_{D} \sqrt{2}}\right)$

where $M$ and $S_{D}$ are the mean and the standard deviation of the lognormal distribution and erf is the Gauss error function; for each formulation two parameters $\left(M\right.$ and $S_{D}$ ) were then extracted from a well fitted result. A statistical analysis could therefore be performed from these variables:

- The equivalent diameter $d_{m}$ which is the median value of the distribution

$d_{m}=e^{M}$

- The dissymmetry coefficient

$S=\left(e^{S_{D}^{2}}+2\right) \sqrt{e^{S_{D}^{2}}-1}$

A higher dissymmetry coefficient means a more heterogeneous distribution.

- The agglomeration rate

$A=d_{m} / d_{e l}$ 

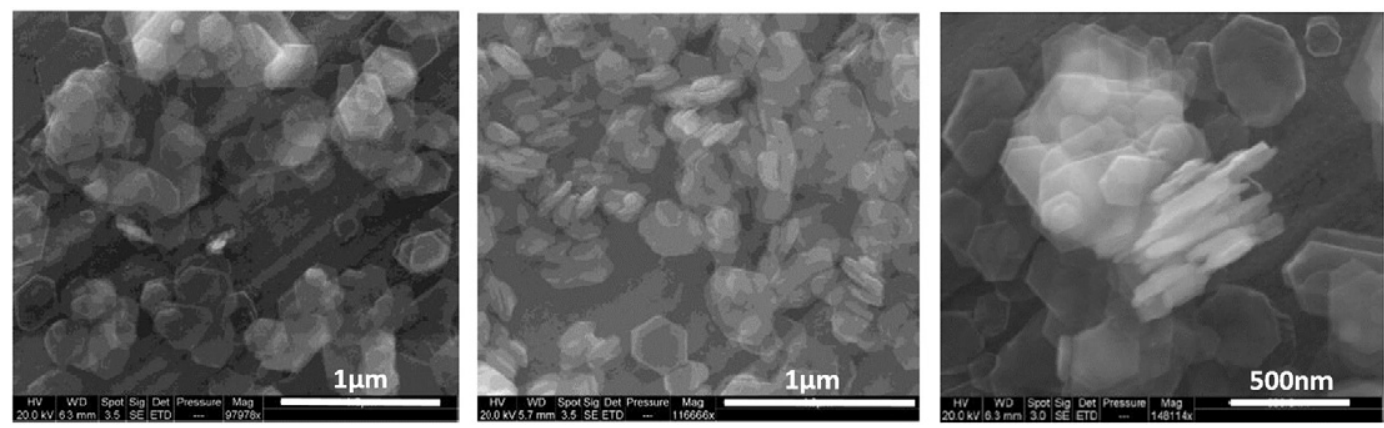

Fig. 1. SEM image of kaolinite $K_{1}$ (left), $K_{2}$ (middle) native particles and (right) $K_{2}$ agglomerates within the polymer matrix.

- The interparticle distance

$$
L=d_{m}\left[C\left(\frac{\pi}{6 \phi_{p}}\right)^{\frac{1}{3}} e^{S_{D}{ }^{2}}-e^{S_{D}{ }^{2} / 2}\right]
$$

where $C$ is a constant value depending on the compactness of stacking. For the sake of simplicity and for all formulations $C$ was assumed equal to 1 (which corresponds to a cubic stacking). The equivalent diameter is not enough to explain the composite mechanical behaviour. Particle density is usually described through the distance between the edges of two adjacent particles and is related to the confined matrix thickness (Michler, 1993). It is possible but complicated to evaluate a mean particle distance from the position of each particle (Hamming et al., 2009). A simplified interparticle distance evaluation was chosen in which a regular compactness stacking of the objects was considered:

\subsubsection{Mechanical testing (quasi-static and dynamic)}

Uniaxial tensile tests were carried out using a Zwick TH010 universal testing machine according to the ISO 527 standard (ISO 527-2, 2012). The crosshead speed depended on investigated properties: $1 \mathrm{~mm} / \mathrm{min}$ to describe linear behaviour and $50 \mathrm{~mm} / \mathrm{min}$ for the non-linear behaviour until breakage. The software used was TestXpert ${ }^{\circledR}$ and allowed the recording of time, load $(F)$ and elongation $(\varepsilon)$. The nominal stress was defined by the following expression: $\sigma=F / S_{0}$ where $S_{0}$ was the initial sample section $\left(40 \mathrm{~mm}^{2}\right)$. Young's modulus $(E)$ value was given by the slope, calculated between 0 and $1 \%$ elongation of the curve giving $\sigma$ vs. axial $\varepsilon$. Out of this range of elongation, the nominal stress reached a maximum (called the yield stress) corresponding to the value $\sigma_{\text {yield }}$ at the strain $\varepsilon_{\text {yield }}$.

Instrumented Charpy impact tests (CEAST 9340, INSTRON®) were performed on standard notched Charpy specimens (Fig. 2b). The specimen was impacted by a pendulum hammer of $m=3.14 \mathrm{~kg}$ at an impact velocity of $1.6 \mathrm{~m} / \mathrm{s}$; the drop height was $130 \mathrm{~mm}$ which corresponded to a striking hammer energy up to $4 \mathrm{~J}$. The instrumentation enabled the evaluation of the load $F(t)$ as well as instantaneous displacement of the specimen $u(t)$ :

$v(t)=v_{0}-\left(\frac{1}{m}\right) \int_{0}^{t} F(t) d t, u(t)=\int_{0}^{t} v(t) d t$

where $v(t)$ was the instantaneous velocity of the impactor.

From the load evolution, a useful global parameter, the impact energy, could be deduced:

$J=\int_{0}^{v} F(v) d v$

\subsubsection{Flame retardancy using a cone calorimeter}

The flame retardancy of PA6 composites was characterized by cone calorimetry using a FTT apparatus according to the ISO 5660 standard (ISO 5660-1, 2015). This technique has been widely used to describe polymer flammability and particularly for polymer-clay nanocomposites (Schartel, 2007). In this study, irradiance was set at $50 \mathrm{~kW} / \mathrm{m}^{2}$. Tests were duplicated for all composites to ensure reproducibility. Cone calorimeter experiments provided several parameters: Time to ignition (TTI), peak of heat release rate (pHRR), total heat release (THR), which was formally the integral of the HRR curve with respect to the time, effective heat of combustion (EHC) and mass loss.

\section{Results, analysis and discussion}

\subsection{Morphological properties}

SEM images of composites revealed the presence of large and well distributed aggregates of kaolinite stacks (see for example Fig. 3 for the $\mathrm{K}_{2} \mathrm{PA}$ composite).

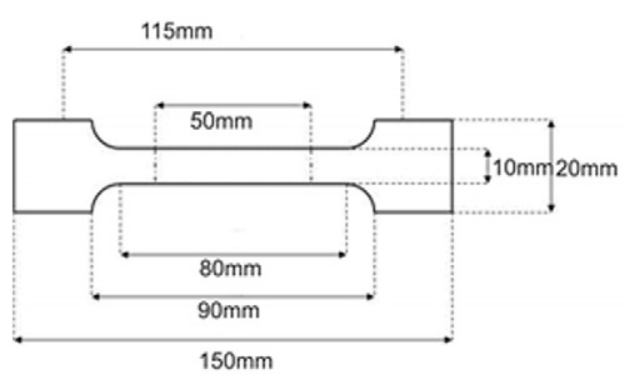

(a)

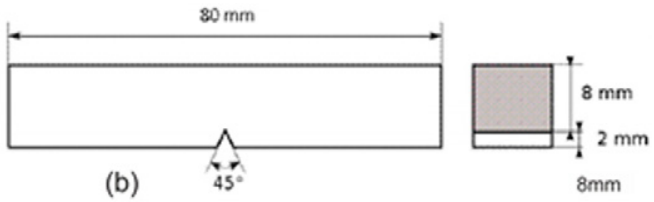

(c)

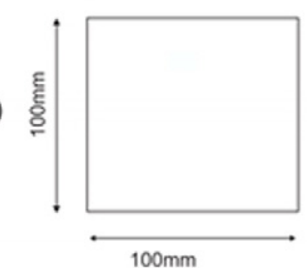

Fig. 2. Standard test specimens. (a) Tensile (ISO 527-2 1A), thickness 4 mm; (b) Charpy impact; (c) Cone calorimeter tests, thickness 4 mm. 
Table 2

Materials under study.

\begin{tabular}{llllllll}
\hline Sample & $\mathrm{PA}$ & $\mathrm{K}_{1} \mathrm{PA}$ & $\mathrm{K}_{1 \mathrm{~A}} \mathrm{PA}$ & $\mathrm{K}_{1 \mathrm{E}} \mathrm{PA}$ & $\mathrm{K}_{2} \mathrm{PA}$ & $\mathrm{K}_{2 \mathrm{~A}} \mathrm{PA}$ & $\mathrm{K}_{2 \mathrm{E}} \mathrm{PA}$ \\
\hline Filler & - & $\mathrm{K}_{1}$ & $\mathrm{~K}_{1}$ & $\mathrm{~K}_{1} \mathrm{~A}$ & $\mathrm{~K}_{2}$ & $\mathrm{~K}_{2}$ & $\mathrm{~K}_{1}$ \\
Grafting & - & - & $\mathrm{A}$ & $\mathrm{E}$ & - & $\mathrm{A}$ & $\mathrm{E}$ \\
\hline
\end{tabular}

The morphological characteristics of all the PA6 composites have been summarized in Table 3. Particles were highly agglomerated in the composite and the smallest particles led to the biggest agglomerates ( see parameter $A$ in Table 3, which is five times larger for the $K_{2}$ particle types). Hence, extrusion process conditions did not allow for obtaining a fine dispersion of kaolinite particles in the matrix. Except for the $\mathrm{K}_{1 \mathrm{~A}}$ particles, the surface treatment induced a reduction of both the agglomerate size $\left(d_{m}\right)$ and the level of agglomeration $(A)$. The coefficient $S$ was not related to $d_{m}$; it only revealed the heterogeneity of the agglomerate size. The interparticle distance $(L)$ was defined from all the previous parameters. Even though a dispersion assumption has been chosen to establish Eq. (5), this parameter was a suitable tool to compare the formulations. The surface treatments led to an increase in the interparticle distance. Unexpectedly the same trend is not observed for the $K_{2}$ particles modified with the A treatment, the compactness of stacking could be less regular in this case.

\subsection{Relations between morphology and mechanical/fire properties}

\subsubsection{Mechanical properties}

The whole stress/strain profile of the materials is given in Fig. 4. As commonly observed for these kinds of material, the nominal stress reached a maximum (called the yield stress) corresponding to the value $\sigma_{\text {yield }}$ at the strain $\varepsilon_{\text {yield }}$. Unexpectedly, it appears that the $\mathrm{K}_{2}$ specimen exhibits mostly a failure in brittle mode while $\mathrm{K}_{1} / \mathrm{PA} 6$ composites were much more ductile, independently of the surface treatment. Does the composite microstructure explain these observations? This will be the point of the paragraph concerning impact tests. The mechanical properties of all the PA6 composites are summarized in Table 4.

Kaolinite filler incorporation led, as expected, to an enhancement of elastic properties. On the basis of the Mori Tanaka model, Tandon and Weng (TW) (1984) proposed an analytical solution for the longitudinal elastic modulus $(E)$ of an isotropic matrix filled with aligned spheroidal inclusions:

$$
\frac{E}{E_{m}}=\frac{1}{1+\frac{\phi_{p}\left(A_{1}+2 \nu_{m} A_{2}\right)}{A_{3}}}
$$

where $E_{m}$ and $\nu_{m}$ denote the Young's modulus and Poisson ratio of PA6 matrix ( $E_{m}$ is displayed in Table 4 and $\nu_{m}$ is assumed, according to the literature (Sato et al., 2005), to be around 0.35) and $A_{1}, A_{2}$, and $A_{3}$ are related to the Eshelby tensor components and to the properties of the
Table 3

Morphological characteristics of the PA6 composites with the $100 \times, 1000 \times$, and $20,000 \times$ scale factors.

\begin{tabular}{lllllll}
\hline Name & $\begin{array}{l}M \\
\mu \mathrm{m}\end{array}$ & $S_{D}$ & $\begin{array}{l}d_{m} \\
\mu \mathrm{m}\end{array}$ & $S$ & $A$ & $\begin{array}{l}L \\
\mu \mathrm{m}\end{array}$ \\
\hline $\mathrm{PA}$ & - & - & - & - & - & - \\
$\mathrm{K}_{1} \mathrm{PA}$ & 1.72 & 1.62 & 5.6 & 10.1 & 6.2 & 97.1 \\
$\mathrm{~K}_{1 \mathrm{~A}} \mathrm{PA}$ & 1.86 & 1.61 & 6.4 & 8.1 & 7.1 & 106.1 \\
$\mathrm{~K}_{1 \mathrm{E}} \mathrm{PA}$ & 1.68 & 1.67 & 5.4 & 11.9 & 6.1 & 111.4 \\
$\mathrm{~K}_{2} \mathrm{PA}$ & 1.90 & 1.60 & 6.7 & 7.7 & 33.5 & 107.7 \\
$\mathrm{~K}_{2 \mathrm{~A}} \mathrm{PA}$ & 1.77 & 1.56 & 5.9 & 7.7 & 29.5 & 83.7 \\
$\mathrm{~K}_{2 \mathrm{E}} \mathrm{PA}$ & 1.76 & 1.64 & 5.8 & 10.3 & 29.0 & 109.0 \\
\hline
\end{tabular}

inclusions and the matrix (elastic constants, inclusion volume fraction and aspect ratio). The particle Young's modulus and Poisson ratio were equal to $180 \mathrm{MPa}$ and 0.20 for both kaolinites, as reported by Chen and Avans (2006). Prediction from the TW model slightly overestimated the experimental modulus (6750 MPa and $5750 \mathrm{MPa}$ for $\mathrm{K}_{1}$ and $\mathrm{K}_{2}$ kaolinites respectively) but it was significantly higher for the $\mathrm{K}_{1}$ particles (with a higher aspect ratio), according to the experimental values and to the literature (Shen et al., 1995). It appeared that surface treatment did not significantly impact the material's elasticity. In fact, the Young's modulus was evaluated at a low level of strain inducing only a little disruption of the interfacial area (Levita et al., 1989). Nevertheless, surface treatment could modify the matrix (crystallinity) and filler dispersion (Wang and Velankar, 2006). Considering the results of Tables 3 and 4, there was no obvious relation between the median diameter and the Young's modulus. However, a drastic decrease was observed as the level of agglomeration increased $\left(K_{2}\right.$ particles were much more agglomerated than $\mathrm{K}_{1}$ ones, see Table 3 ).

Usually, yield stress increases and yield strain decreases with the incorporation of well dispersed rigid particles. It is recognized that it can be ascribed to a good adhesion between fillers and matrix (which is responsible for the stress increasing) with reduction of the matrix volume which allows deformation (responsible for the strain decreasing). Some authors explained the stress increasing by the particle size and shape or the interface of matrix/particle behaviour (Alter, 1965; Okuno and Woodhams, 1974; Shen et al., 1995; Turcsányi et al., 1988). Without surface treatment, the $K_{2}$ particles (with the lower aspect ratio) led to the lower yield stress. Nevertheless they offered the larger specific surface area leading a priori to a good efficiency of grafting. The key parameter for the yield stress seemed to be the median diameter $d_{m}$ (Fig. 5a) as $\sigma_{\text {yield }}$ depended linearly on the median diameter. The median diameter value was a direct consequence of the particle size, shape and treatment. Concerning the yield strain, the same trend was observed for each kind of kaolinite. $\varepsilon_{\text {yield }}$ decreased drastically with the level of aggregation $(A)$ (Fig. 5b). Although on different deformation levels, the same sensitivity to the aggregation parameter $(A)$ was detected for the two types of particles $\left(\mathrm{K}_{1}\right.$ and $\left.\mathrm{K}_{2}\right)$.

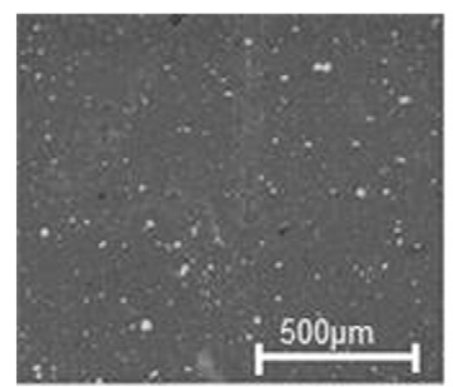

(a) scale factor 100

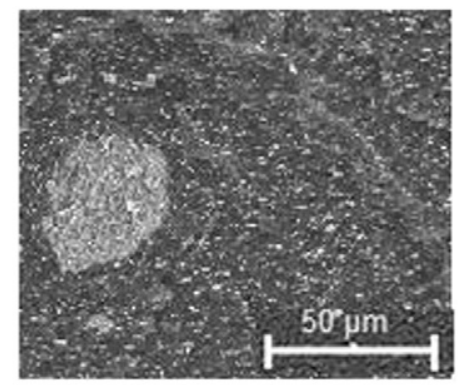

(b) scale factor 1000

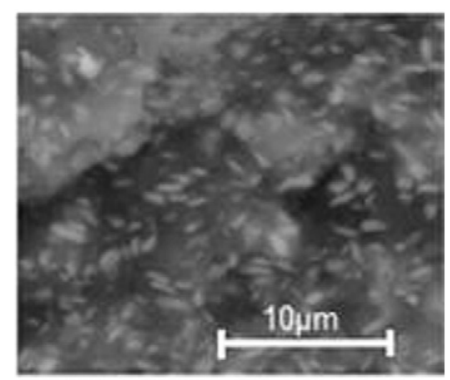

(c) scale factor 20000

Fig. 3. SEM micrographs of PA6 with 30 wt.\% of $K_{2}$, scale factors (a) 100, (b) 1000 and (c) 20,000. 

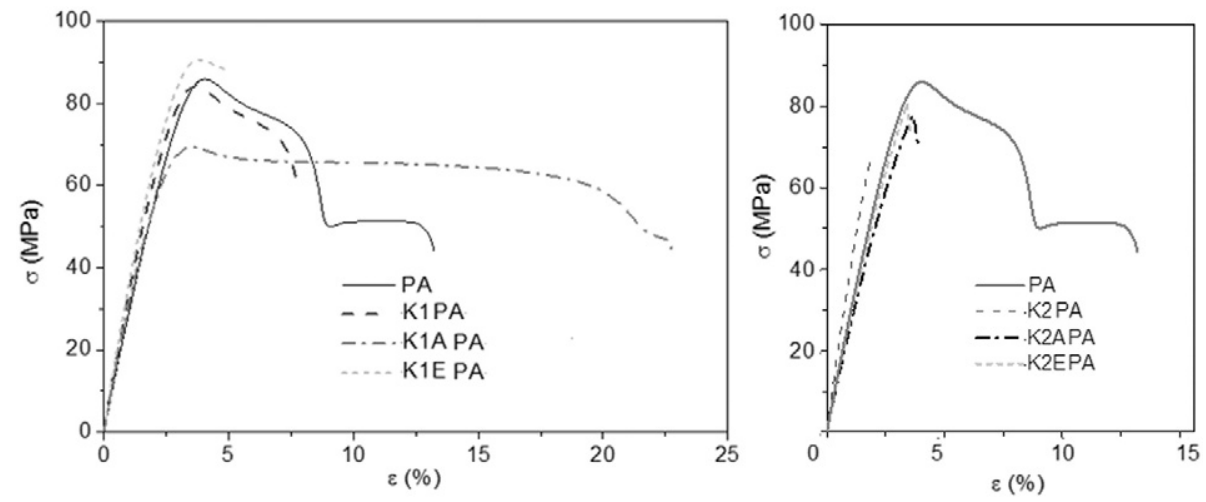

Fig. 4. Stress vs. strain in uniaxial tensile tests for PA6 composites.

To better characterize the efficiency of interface modification, the model proposed by Pukansky was used (Demjén et al., 1998). In this model, a $B$ parameter is introduced to describe the interfacial cohesion:

$\left.B=\frac{1}{\phi_{p}} \ln \frac{\sigma_{\text {yield }}}{\sigma_{P A} \text { yield }} \frac{1-2.5 \phi_{p}}{1-\phi_{p}}\right)$

The higher is $B$, the better is the kaolinite/PA6 interfacial cohesion. A first observation was that a good kaolinite/PA6 interfacial cohesion led to a decrease in agglomerate size (Fig. 6a). The median diameter appeared to increase inversely with the cohesion between matrix and aggregates. The cohesion parameter could be controlled by a suitable surface treatment and could therefore influence the particle dispersion.

The impact force vs time for the PA6 composites is plotted in Fig. $6 \mathrm{~b}$. The impact behaviour was highly dependent on filler and/or surface treatment. All specimens were totally broken after the impact and fillers provided additional toughening effects. The fracture morphology of

Table 4

Mechanical properties (Young's modulus, yield stress and strain, impact energy) of the PA6 composites.

\begin{tabular}{lllll}
\hline Name & $E(\mathrm{MPa})$ & $\sigma_{\text {yield }}(\mathrm{MPa})$ & $\varepsilon_{\text {yield }}$ & $J(\mathrm{~J})$ \\
\hline $\mathrm{PA}$ & $3419 \pm 89$ & $86.8 \pm 0.75$ & $3.6 \pm 0.12$ & $2.9 \pm 0.9$ \\
$\mathrm{~K}_{1} \mathrm{PA}$ & $6387 \pm 67$ & $93.0 \pm 2$ & $3.2 \pm 0.08$ & $1.7 \pm 0.1$ \\
$\mathrm{~K}_{1 \mathrm{~A}} \mathrm{PA}$ & $6200 \pm 87$ & $78.8 \pm 2$ & $3.3 \pm 0.15$ & $3.2 \pm 0.6$ \\
$\mathrm{~K}_{1 \mathrm{E}} \mathrm{PA}$ & $6300 \pm 93$ & $93.5 \pm 0.3$ & $3.9 \pm 0.20$ & $3.8 \pm 0.8$ \\
$\mathrm{~K}_{2} \mathrm{PA}$ & $4581 \pm 59$ & $67.2 \pm 3.5$ & $1.9 \pm 0.32$ & $1.2 \pm 0.2$ \\
$\mathrm{~K}_{2 \mathrm{~A}} \mathrm{PA}$ & $4641 \pm 200$ & $87.6 \pm 5$ & $4.8 \pm 1.09$ & $4.6 \pm 0.3$ \\
$\mathrm{~K}_{2 \mathrm{E}} \mathrm{PA}$ & $4500 \pm 100$ & $86.6 \pm 5$ & $4.9 \pm 0.86$ & $3.5 \pm 0.2$ \\
\hline
\end{tabular}

each broken sample was observed by microscopy to identify the failure mode (ductile/brittle). Literature results (Bartczak and Pracella, 2006; Fu and Wang, 1992; Yun et al., 2003) revealed the undeniable relationship between rupture and interfacial cohesion in composites. In the case of no adhesion, rupture will be conditioned by the matrix properties; if the interface is brittle, stress concentration around particles will be increased and will lead to a brittle breakdown. On the contrary, a ductile interface will produce particle cavitation (Yun et al., 2003). Beyond these observations, it seemed that rupture depended mainly on the biggest agglomerates (Fu and Wang, 1992). Some authors defined a size criterion in relation with the fragile/ductile composite breakdown (Bartczak and Pracella, 2006). According to these authors and ignoring stochastic effects related to large agglomerates observed for each formulation, it was chosen to deal with the largest magnification $(\times 100)$; these results are summarized in Table 5 with the associated mode of failure. A good correlation was found between resilience and interparticle distance through a sigmoid function (Fig. 7). This graph confirms the existence of a critical interparticle value related to the ductile-brittle material transition.

\subsubsection{Flame retardancy}

With regard to the previous part the mechanical properties could be related to the morphology of composites and particularly to the agglomerates. Flame retardancy also depends on the dispersion of nanoparticles. Such a relationship has been evidenced in polymers containing low contents of specific nanoparticles like multiwalled carbon nanotubes or clays (Bourbigot et al., 2006; Kashiwagi et al., 2007) even if the percentages of incorporation in these polymers were far below the one used in this study. Particle dispersion has also a strong influence in formulations in which various particulate components are present (Quach et al., 2012; Si et al., 2007). Nevertheless, the role of dispersion
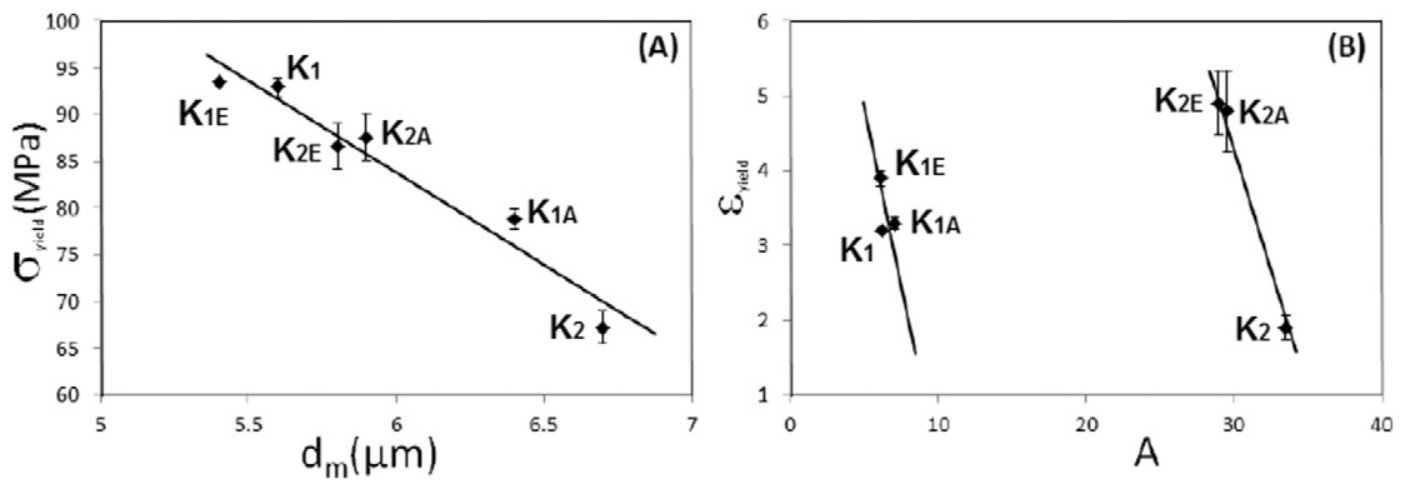

Fig. 5. (a) Yield stress as a function of median diameter. (b) Yield strain as a function of agglomeration rate. 

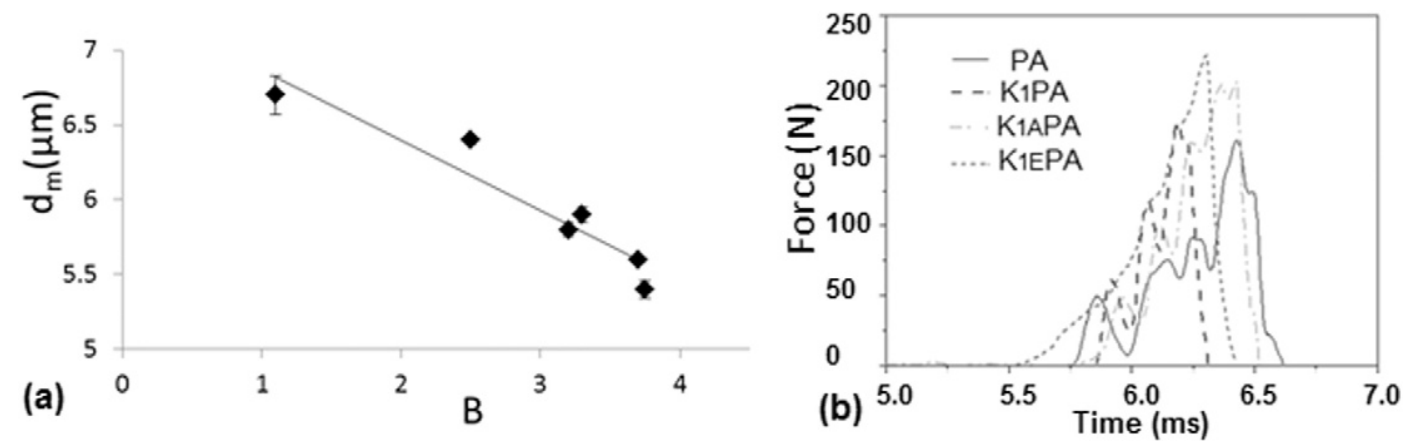

Fig. 6. Kaolinite/polyamide interfacial cohesion versus median diameter (a). Impact force versus time for the PA6 composites (b).

on flame retardancy in highly filled polymers has not been clearly shown. The following is a first attempt to assess the influence of morphology (i.e. in this study the characteristics of the agglomerates) on flame retardancy of the highly filled polyamide composites.

The percolation of fillers which corresponds to the formation of a long-range connectivity in random system is a phenomenon able to modify significantly the behaviour of materials. For example, Wang and Zhang (2012) indicated that the formation of a mineral crust contributed to a significant reduction of the heat release rate, provided that mineral particles were percolated. Lu and Mai (2005) proposed the evaluation of the critical volume fraction of the percolation threshold $\phi_{c}$ for the barrier properties of aligned clays as follows:

$\phi_{c}=\frac{p_{c}}{\alpha}$

where $p_{c}$ is the critical content for minimum permeability. This latest value could be deduced from a stochastic model: the Monte Carlo Random Graph model (Erdös and Rényi, 1959). In the case of clays, $p_{c}=$ 0.718 (Lu and Mai, 2005). The same value for the kaolinite particles was assumed even if total dispersion at a nanoscale was not achieved in the present application. The critical volume fractions evaluated from Eq. (10) were $7 \%$ and $14 \%$ respectively for $K_{1}$ and $K_{2}$ particles, corresponding to the mass fractions of $15 \%$ and $28 \%$ respectively. In the present study the level of mass incorporation was 30\%. Therefore in the composites, $\mathrm{K}_{1}$ particles should be percolated (the mass fraction is far beyond the critical mass fraction) while it was not so obvious for $\mathrm{K}_{2}$ particles. Thus the sensitivity of flammability to agglomeration might in this case be hidden by the percolation phenomena. This study was therefore focused on $\mathrm{K}_{1} \mathrm{PA} 6, \mathrm{~K}_{1 \mathrm{~A}} \mathrm{PA} 6$, and $\mathrm{K}_{1 \mathrm{E}} \mathrm{PA} 6$ composites. Nevertheless the cone calorimeter test was also carried out on $\mathrm{K}_{2} / \mathrm{PA} 6$ (untreated) composite for comparison.

The main cone calorimeter results are displayed in Fig. 8 and the fire parameters are reported in Table 6 . The results were reproducible within $\pm 10 \%$ (see average curves in Fig. 8). The theoretical residue mass was calculated considering that the whole polymer fraction was volatilized during the test and that kaolinite was dehydroxylated (L'vov and Ugolkov, 2005). Except for $\mathrm{K}_{1 \mathrm{E}} \mathrm{PA}$ composite, the HRR curve exhibited a constant increase of HRR up to a peak followed by a rapid decrease

Table 5

Morphological characteristics of the PA6 composites with the $100 \times$ scale factor.

\begin{tabular}{|c|c|c|c|c|c|c|c|}
\hline Name & $\begin{array}{l}M \\
\mu \mathrm{m}\end{array}$ & $S_{D}$ & $\begin{array}{l}d_{m} \\
\mu \mathrm{m}\end{array}$ & $S$ & $\begin{array}{l}L \\
\mu \mathrm{m}\end{array}$ & $J / J_{P A}$ & Failure mode \\
\hline $\mathrm{K}_{1} \mathrm{PA}$ & 3.16 & 1.99 & 23.5 & 12.0 & 1303 & $1.2 \pm 0.05$ & Ductile \\
\hline $\mathrm{K}_{1 \mathrm{~A}} \mathrm{PA}$ & 3.13 & 1.94 & 22.9 & 7.2 & 1344 & $1.1 \pm 0.1$ & Ductile \\
\hline $\mathrm{K}_{1 \mathrm{E}} \mathrm{PA}$ & 2.88 & 1.96 & 17.8 & 10.1 & 1149 & $1.3 \pm 0.08$ & Ductile \\
\hline $\mathrm{K}_{2} \mathrm{PA}$ & 3.48 & 1.99 & 32.7 & 7.1 & 2588 & $0.4 \pm 0.02$ & Brittle \\
\hline $\mathrm{K}_{2 \mathrm{~A}} \mathrm{PA}$ & 2.66 & 1.81 & 14.3 & 8.0 & 492 & $1.6 \pm 0.2$ & Ductile \\
\hline $\mathrm{K}_{2 \mathrm{E}} \mathrm{PA}$ & 3.00 & 1.95 & 20.1 & 12.5 & 1723 & $0.6 \pm 0.11$ & Brittle \\
\hline
\end{tabular}

due to the fuel shortage. Such a curve shape revealed poor fire performances. On the contrary, the curve for $\mathrm{K}_{1 \mathrm{E}} \mathrm{PA}$ reached a low pHRR followed by a plateau, i.e. a stabilization of HRR due to the kaolinite protective layer. The slight increase of HRR at the end of the test may be due to the breakdown of the protective layer. The maximum pHRR reduction was of $44 \%$ for $\mathrm{K}_{1} \mathrm{PA}, 54 \%$ for $\mathrm{K}_{1 \mathrm{~A}} \mathrm{PA}$, and $65 \%$ for $\mathrm{K}_{1 \mathrm{E}} \mathrm{PA}(42 \%$ for $\mathrm{K}_{2} \mathrm{PA}$ ). In fact, to improve both mechanical properties and reaction to fire, a good particle dispersion must be achieved regardless of their sizes (as was the case for the formulation $\mathrm{K}_{1 \mathrm{E}} \mathrm{PA}$ ).

The residue content was in all cases close to the theoretical residue, which means that the polymer was fully degraded during the test and that no significant char was formed. This was confirmed by the residue aspect (see Fig. 9). The residue was grey with only small traces of black char. The effective heat of combustion was similar for all materials, despite the release of water from the kaolinite. Nevertheless, the water released from kaolinite was only $15 \%$ and the filler fraction was $30 \%$. Therefore, it was not surprising that EHC did not decrease markedly. Finally THR of composites was close to $70 \%$ of the value for pure PA6 which confirmed the previous observations. Two parameters changed significantly with kaolinite particles: TTI and pHRR. No correlation was found between TTI and morphological parameters measured by image analysis. The ignition was dependent on many physical and chemical phenomena. The dispersion of particles could affect the TTI through several phenomena. Particles decrease the heat absorption in-depth (Fina et al., 2013; Sonnier et al., 2015) or can modify the emissivity or the thermal conductivity (Kashiwagi et al., 2004). The decrease of TTI could be due to a modification of heat transfer caused by the presence of aggregates (Clerc et al., 2005; Wang and Zhang, 2012), which increased locally the polymer temperature and the concentration of combustible volatiles in the gaseous phase surrounding the sample

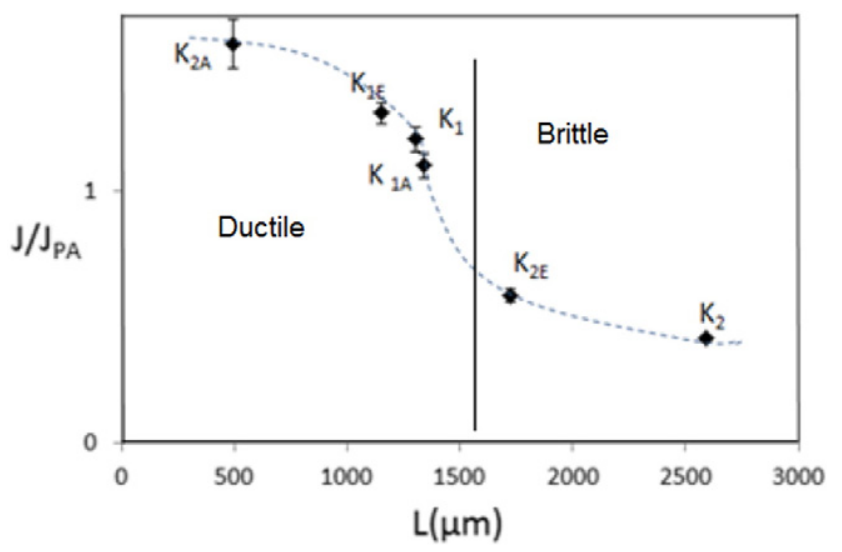

Fig. 7. Normalized impact energy $\left(J / J_{P A}\right)$ versus interparticle distance $(L)(100 \times$ magnification). 

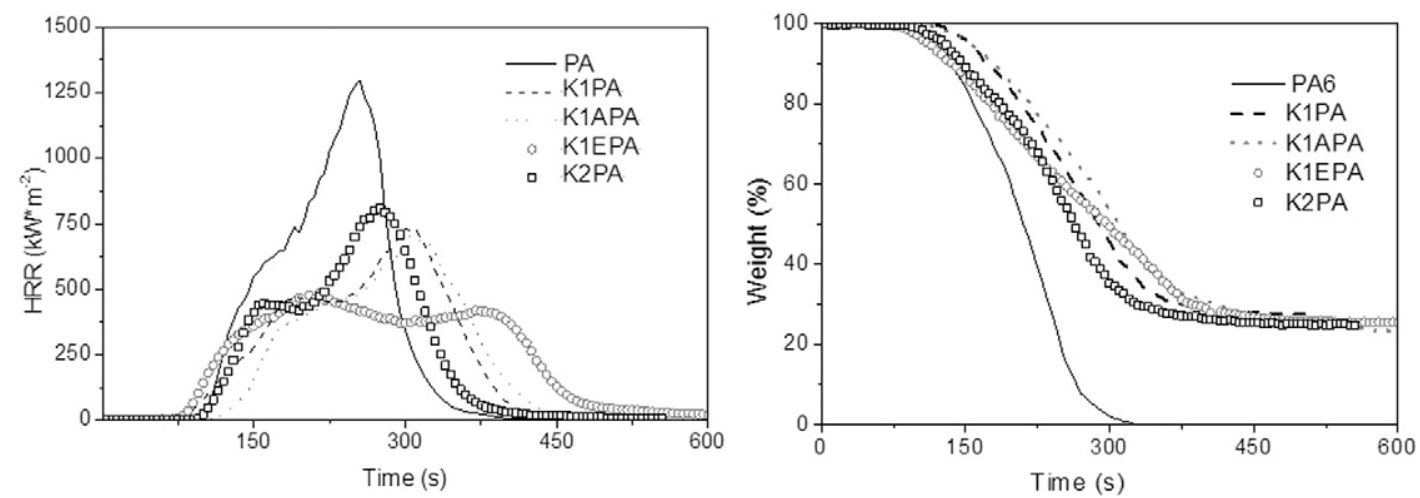

Fig. 8. Heat release rate (HRR) curves (left) and mass loss curves (right) of pristine PA6 and PA6 composites vs time.

(Drysdale, 2011). Viscosity (which is dependent on particle dispersion) also influences the heat transfer (a low viscosity allows convective flow, which can evacuate heat from the surface to the bulk) and the bubbling (bubbling can change the optical properties of the surface and then the heat absorption) (Oztekin et al., 2012). A more detailed study is needed to assess if the kaolinite dispersion impacts the TTI. On the contrary, some evidences could be found showing that pHRR as reported in Table 6 may be dependent on the largest agglomerates defined in Table 5. The change in pHRR versus the interparticle distance $L$ is demonstrated by the plot of Fig. 10. The higher was the interparticle distance, the higher was the pHRR. In other words, the better was the distribution of the agglomerates the lower was the pHRR. Viscosity was strongly dependent on the filler dispersion. Generally a percolated network promotes a high viscosity while large agglomerates tend to decrease the viscosity. Viscosity has been proved as a very influential parameter controlling the pHRR in various systems (Kashiwagi et al., 2008) including polymers filled with moderate to high loadings of mineral fillers (Batistella et al., 2014). The preliminary results shown in the present work seem to confirm the beneficial role of a high viscosity on the heat release rate. To decrease the pHRR, a great challenge is the decrease of kaolinite agglomeration before and during the process in order to reach a better dispersed system. Indeed, only

Table 6

Fire properties of PA6 composites.

\begin{tabular}{lccllll}
\hline Name & $\begin{array}{l}\text { pHRR } \\
\left(\mathrm{kW} / \mathrm{m}^{2}\right)\end{array}$ & TTI $(\mathrm{s})$ & $\begin{array}{l}\text { THR } \\
\left(\mathrm{MJ} / \mathrm{m}^{2}\right)\end{array}$ & $\begin{array}{l}\text { THR } \\
(\mathrm{kJ} / \mathrm{g})\end{array}$ & $\begin{array}{l}\text { Residue } \\
(\%)\end{array}$ & $\begin{array}{l}\mathrm{EHC} \\
(\mathrm{kJ} / \mathrm{g})\end{array}$ \\
\hline $\mathrm{PA}$ & $1352 \pm 48$ & $79 \pm 5$ & $149 \pm 1$ & 28 & 0.1 & $28.2 \pm 2$ \\
$\mathrm{~K}_{1} \mathrm{PA}$ & $750 \pm 50$ & $72 \pm 7$ & $125 \pm 2$ & 19.7 & 26.4 & $29.8 \pm 1$ \\
$\mathrm{~K}_{1 \mathrm{~A}} \mathrm{PA}$ & $614 \pm 25$ & $100 \pm 20$ & $100 \pm 20$ & 19 & 25.8 & $28.8 \pm 2$ \\
$\mathrm{~K}_{1 \mathrm{E}} \mathrm{PA}$ & $470 \pm 12$ & $50 \pm 5$ & $50 \pm 5$ & 21 & 25.0 & $29.8 \pm 2$ \\
$\mathrm{~K}_{2} \mathrm{PA}$ & $780 \pm 20$ & $80 \pm 8$ & $80 \pm 8$ & 19.7 & 26.0 & $29.8 \pm 1$ \\
\hline
\end{tabular}

four formulations were tested and these results need to be confirmed in a further study.

\section{Conclusion}

Kaolinite/PA6 composites were prepared by compounding and injection-moulding. Some of the kaolinites were surface treated and the composite microstructures were characterized via image analysis at different magnifications. The composites thus prepared show a wide range of microstructures, all of them however being highly agglomerated. These microstructures were described via statistical image analysis from the primary particle to the biggest agglomerates. The influence of the microstructure on both flammability and mechanical properties was investigated. The mechanical testing revealed the strong relationship between the yield stress/strain, the resilience and the microstructure. The Young's modulus decreased slightly as the interparticle distance between particles increased, but in the range of investigated interparticle values the sensitivity to this parameter is not predominant. This result is in accordance with the literature: the Young's modulus is not the key parameter to describe the effect of functionalization. However, the yield stress was clearly decreasing when the median diameter increased and the yield strain followed the same trend with the level of agglomeration. The pHRR was reduced when a better dispersion of the biggest agglomerates was reached. These parameters seem to depend on the microstructure in its totality which requires a multi-scale morphological analysis including all the observable particle sizes. On the contrary, dynamic Charpy impact tests and flammability testing were sensitive to the biggest agglomerates (studied on the basis of morphological analysis in high magnification): the resilience decreased when the interparticle distance increased and above a critical value of this parameter, brittle fracture governed ultimate properties.
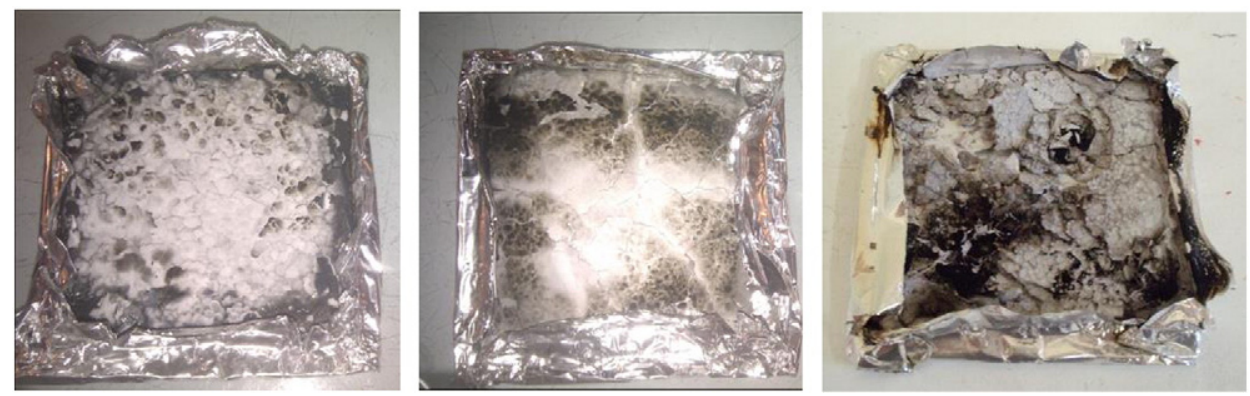

Fig. 9. Photographs of residues of PA6 composites: (left) $K_{1} P A$, (middle) $K_{1} A P A$ and (right) $K_{1 E} P A$ in the cone calorimeter test. 


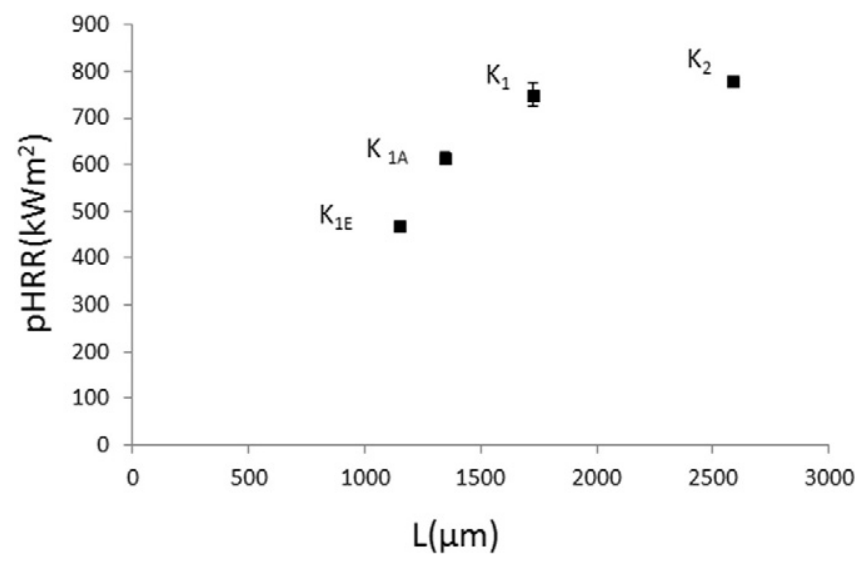

Fig. 10. Change in pHRR versus interparticle distance $L$.

\section{References}

Alter, H., 1965. Filler particle size and mechanical properties of polymers. J. Appl. Polym. Sci. 9 (4), 1525-1531.

ASTM D6110-10, 2014. Standard Tests Method for Determining the Charpy Impact Resistance of Notched Specimens of Plastics. ASTM International, West Conshohocken, PA.

ASTM D638-14, 2014. Standard Tests Method for Tensile Properties of Plastics. ASTM International, West Conshohocken, PA.

Bartczak, Z., Pracella, M., 2006. Blends of propylene-ran-ethylene and propylene-ran-(1butene) copolymers: Crystal superstructure and mechanical properties. Eur. Polym. J. 42 (8), 1819-1829.

Batistella, M., Otazaghine, B., Sonnier, R., Caro-Bretelle, A.S., Petter, C., Lopez-Cuesta, J.M., 2014. Fire retardancy of ethylene vinyl acetate/ultrafine kaolinite composites. Polym. Degrad. Stab. 100, 54-62.

Blumstein, A., 1965. Polymerization of absorbed monolayers: II. Thermal degradation of the inserted polymers. J. Polym. Sci. A 3, 2665-2673.

Bourbigot, S. Le, Bras, M., Dabrowski, F., Gilman, J.W., Kashiwagi, T., 2000. PA-6 clay nanocomposite hybrid as char forming agent in intumescent formulations. Fire Mater. 24 201-208.

Bourbigot, S., Duquesne, S., Jama, C., 2006. Polymer nanocomposites: how to reach low flammability? Macromol. Symp. 233, 180-190.

Chen, B.Q., Avans, J.R.G., 2006. Elastic moduli of clay platelets. Scr. Mater. 54 (9), 1581-1585.

Clerc, L., Ferry, L., Leroy, E., Lopez-Cuesta, J.M., 2005. Influence of talc physical properties on the fire retarding behaviour of (ethylene-vinyl acetate copolymer/magnesium hydroxide/talc) composites. Polym. Degrad. Stab. 88, 504-511.

Demjén, Z., Pukánszky, B., Nagy, J., 1998. Evaluation of interfacial interaction in polypropylene/surface treated $\mathrm{CaCO}_{3}$ composites. Compos. A: Appl. Sci. Manuf. 29, 323-329.

Drysdale, D. 2011. An Introduction to Fire Dynamics. 3rd ed. Wiley, Chichester.

Erdös, P., Rényi, A., 1959. On random graphs. Publ. Math. 6, 290-297.

Fina, A., Abbenhuis, H.C.L., Tabuani, D., Frache, A., Camino, 2006. Polypropylene meta functionalised POSS nanocomposites: a study by thermogravimetric analysis. Polym. Degrad. Stab. 91, 1064-1070.

Fina, A., Feng, J., Cuttica, F., 2013. In-depth radiative heat transmittance through polypropylene/nanoclay composites. Polym. Degrad. Stab. 98, 1030-1035.

Friederich, B., Laachachi, A., Ferriol, M., Ruch, D., Cochez, M., Toniazzo, V., 2010. Tentative links between thermal diffusivity and fire-retardant properties in poly(methy methacrylate)-metal oxide nanocomposites. Polym. Degrad. Stab. 95, 1183-1193.

Fu, Q., Wang, G., 1992. Polyethylene toughened by rigid inorganic particles. Polym. Eng. Sci. 32 (2), 94-97.

Gérard, C., Fontaine, G., Bourbigot, S., 2010. New trends in reaction and resistance to fire of fire-retardant epoxies. Materials 3, 4476-4499.

Giannelis, E.P. 2004. Polymer layered silicate nanocomposites. Adv Mater. 8 (1), 29-35.

Gilman, J.W., Jackson, C.L., Morgan, A.B., Harris, R., Manias, E., Giannelis, E.P., Wuthenow, M., Hilton, D., Phillips, S.H., 2000. Flammability properties of polymer-layered-silicate nanocomposites. Polypropylene and polystyrene nanocomposites. Chem. Mater. 12, 1866-1873.

Hamming, L.M., Qiao, R., Messersmith, P.B., Brinson, L.C., 2009. Effects of dispersion and interfacial modification on the macroscale properties of $\mathrm{TiO}(2)$ polymer matrix nanocomposites. Compos. Sci. Technol. 69 (11-12), 1880-1886.

ISO 527-2, 2012. Plastics - Determination of Tensile Properties - Part 2: Test Conditions for Moulding and Extrusion Plastics. In: Genève, Switzerland: International Organization for Standardization (ISO) (Ed.), p. 5.

ISO 5660-1, 2015. Reaction to Fire Tests - Heat Release, Smoke Production and Mass Loss Rate - Part 1: Heat Release Rate (Cone Calorimeter Method) and Smoke Production Rate. In: Genève, Switzerland: International Organization for Standardization (ISO) (Ed.), p. 18.
Kashiwagi, T., Grulke, E., Hilding, J., Groth, K., Harris, R., Butler, K., Shields, J., Kharhchneko, S., 2004. Thermal and flammability properties of polypropylene/carbon nanotube nanocomposites. Polymer 45 (12), 4227-4239.

Kashiwagi, Fagan, J., Douglas, J.F., Yamamoto, K., Heckert, A.N., Leigh, S.D., Obrzut, J., Du, F., Lin-Gibson, S., Mu, M., Winey, K.I., Haggenmueller, R., 2007. Relationship between dispersion metric and properties of PMMA/SWNT nanocomposites. Polymer 48, 4855-4866.

Kashiwagi, T., Mu, M., Winey, K., Cipriano, B., Raghavan, S.R., Pack, S., Rafailovich, M., Yang, Y., Grulke, E., Shields, J., Harris, R., Douglas, J., 2008. Relation between the viscoelastic and flammability properties of polymer nanocomposites. Polymer 49, 4358-4368.

L'vov, B.V., Ugolkov, V.L., 2005. Kinetics and mechanism of dehydration of kaolinite, muscovite and talc analyzed thermogravimetrically by the third-law method. J. Therm. Anal. Calorim. 15-22.

Laachachi, A., Leroy, E., Cochez, M., Ferriol, M., Lopez Cuesta, J.M., 2005. Use of oxide nanoparticles and organoclays to improve thermal stability and fire retardancy of poly(methyl methacrylate). Polym. Degrad. Stab. 89, 344-352.

Laachachi, A., Ferriol, M., Cochez, M., Lopez Cuesta, J.M., Ruch, D., 2009. A comparison of the role of boehmite $(\mathrm{AlOOH})$ and alumina $\left(\mathrm{Al}_{2} \mathrm{O}_{3}\right)$ in the thermal stability and flammability of poly(methyl methacrylate). Polym. Degrad. Stab. 94, 1373-1378.

Laoutid, F., Ferry, L., Leroy, E., Lopez Cuesta, J.M., 2006. Intumescent mineral fire retardant systems in ethylene-vinyl acetate copolymer: effect of silica particles on char cohesion. Polym. Degrad. Stab. 91, 2140-2145.

Levita, G., Marchetti, A., Lazzeri, A., 1989. Fracture of ultrafine calcium carbonate/polypropylene composites. Polym. Compos. 10, 39-43.

Lu, C., Mai, Y.W., 2005. Influence of aspect ratio on barrier properties of polymer-clay nanocomposites. Phys. Rev. Lett. 95, 088303.

Michler, G.H., 1993. The role of interparticle distance in maximizing the toughness of high-impact thermoplastics. Acta Polym. 44 (3), 113-124.

Okuno, K., Woodhams, R.T., 1974. Mechanical properties and characterization of phenolic resin syntactic foams. J. Cell. Plast. 10 (5), 237-244.

Oztekin, E.S., Crowley, S.B., Lyon, R.E., Stoliarov, S.I., Patel, P., Hull, T.R., 2012. Sources of variability in fire test data: a case study on poly(aryl ether ether ketone) (PEEK). Combust. Flame 159, 1720-1731.

Peeterbroeck, S., Laoutid, F., Taulemesse, J.M., Monteverde, F., Lopez-Cuesta, J.M., Nagy, J.B., Alexandre, M., Dubois, P., 2007. Mechanical properties and flame-retardant behavior of ethylene vinyl acetate/high-density polyethylene coated carbon nanotube nanocomposites. Adv. Funct. Mater. 17, 2787-2791.

Quach, Y., Cinausero, N., Sonnier, R., Longuet, C., Lopez-Cuesta, J.M., 2012. Barrier effect of flame retardant systems in poly(methyl methacrylate): study of the efficiency of the surface treatment by octylsilane of silica nanoparticles in combination with phosphorous fire retardant additives. Fire Mater. 36 (7), 590-602.

Razak, M.Z.A., Arsad, A., Rahmat, A.R., Hassan, A., 2012. Influence of MMT as reinforcement on rheological behavior, mechanical and morphological properties of recycled PET/ABS thermoplastic nanocomposites. J. Polym. Eng. 32 (3), 177-183.

Riva, A., Zanetti, M., Braglia, M., Camino, G., Falqui, L., 2002. Thermal degradation and rheological behaviour of EVA/montmorillonite nanocomposites. Polym. Degrad. Stab. 299-304.

Rothon, R.N.N., Hornsby, P.R.R., 1996. Flame retardant effects of magnesium hydroxide. Polym. Degrad. Stab. 54, 383-385.

Sato, H., Ono, K., Johnston, C.T., Yamagishi, A., 2005. First-principles studies on the elastic constants of a 1:1 layered kaolinite mineral. Am. Mineral. 90, 1824-1826.

Schartel, B., 2007. Flame Retardant Polymer Nanocomposites. In: Morgan, A.B., Wilkie, C.A. (Eds.), John Wiley \& sons, New York, pp. 107-130.

Shen, Y.L., Finot, M., Needleman, A., Suresh, S., 1995. Effective plastic response of two-phase composites. Acta Metall. Mater. 43, 1701-1722.

Si, M., Zaitsev, V., Goldman, M., Frenkel, A., Peiffer, D.G., Weil, E., Sokolov, J.C., Rafailovich, M.H., 2007. Self-extinguishing polymer/organoclay nanocomposites. Polym. Degrad. Stab. 92, 86-93.

Sonnier, R., Bokobza, L., Concha-Lozano, N., 2015. Influence of multiwall carbon nanotube (MWCNT) dispersion on ignition of poly(dimethylsiloxane)-MWCNT composites. Polym. Adv. Technol. 26 (3), 277-286.

Swoboda, B., Leroy, E., Lopez-Cuesta, J.M., Artigo, C., Petter, C., Sampaio, C.H., 2009. Organomodified ultrafine kaolin for mechanical reinforcement and flame retardancy: an example with recycled PET. In: Hull, R., Kandola, B.K. (Eds.), Fire Retardancy of Polymers. The Royal Society of Chemistry, Oxford (UK) (Chap. 5).

Tandon, G.P., Weng, G.J., 1984. The effect of aspect ratio of inclusions on the elastic properties of unidirectionally aligned composites. Polym. Compos. 5, 327-333.

Turcsányi, B., Pukánszky, B., Tüdõs, F., 1988. Composition dependence of tensile yield stress in filled polymers. J. Mater. Sci. Lett. 7, 160-162.

Villanueva, M.P., Cabedo, L., Lagarón, J.M., Giménez, E., 2010. Comparative study of nanocomposites of polyolefin compatibilizers containing kaolinite and montmorillonite organoclays. J. Appl. Polym. Sci. 115, 1325-1335.

Wang, J., Velankar, S., 2006. Strain recovery of model immiscible blends: effects of added compatibilizer. Rheol. Acta 45, 297-304.

Wang, Y., Zhang, J., 2012. Influences of talc on fire performance of low density polyethylene. Fire. Technol 50 (4), 873-888

Yun, S.U.K.H., Cho, D., Kim, J., Lim, S., Lee, G.W., Park, M.I.N., Lee, S.S., 2003. Effect of silane coupling agents with different organo-functional groups on the interfacial shear strength of glass fiber/Nylon 6 composites. J. Mater. Sci. Lett. 22, 1591-1594. 